much better indices have now been developed, and the search for causal mechanisms (which must surely be multiple) has been made easier by the study, using the newer indices, of subnational populations defined by postcode or municipal wards. Such studies confirm the constancy of the association between deprivation and ill health; and they may also bring to light potentially causal factors which might not appear so clearly in national statistics. In all this work, conveniently brought together in the 1992 edition of The Health Divide, ${ }^{4}$ Peter Townsend has been a major worker, and a stimulant of work in others.

\section{... and after}

The differences in mortality associated with social deprivation are considerable, and they are at their greatest in the very early stages of life. One of our prime recommendations was that children be given a better start in life. We based this on the long term duration of any improvement in health which could be achieved by better maternity or infant care; but that is not the whole story. More recent studies by Marmot in relation to heart disease ${ }^{5}$ and by Barker more generally support the generalisation in the Court report that childhood illness casts long shadows ahead, producing impairment of health years in the future. ${ }^{7}$

In seeking for an explanation of the association between social deprivation and ill health we recognised that on occasion the onset of ill health could lead to impoverishment, and also that shifts of individuals between classes could be statistically confounding. We did, however, adopt the position that in the main it was social deprivation which was the independent variable, damaging health in a variety of ways, acting differently at different stages of life. For children, important factors were lack of safe play areas, domestic overcrowding, and lack appropriate stimulation. For workers, inappropriate living conditions and deleterious lifestyles (some of which are shamefully stimulated by advertising) may have their effects made worse by specific hazards of particular occupations, which may be both poorly paid and intrinsically hazardous. The accumulated burden of a socially deprived life continues to oppress the diminished band of those who survive into old age. Many details have since been added to the picture, but they have in general strengthened its outlines, rather than demanded any radical revision.

Another matter on which we had some discussion within the group was the relative importance, in alleviating the health effects of social deprivation, of measures which could be broadly called social, and of measures directly related to health services. Our view, that poverty and its effects was the root cause of the ill health associated with it, naturally led us to advocate a wider strategy of social measures. After all, the surest way to alleviate the effects of poverty must be to alleviate poverty itself. But since the millenium is not at hand, except perhaps in the most formal sense, it is also worth considering the value of improving health care, even if only as a palliative. At the time of the report there was little quantitative evidence to suggest that specifically medical measures might appreciably reduce mortality at the population level, though their potential to help in individual episodes of illness was well recognised. It has now, however, been shown in several countries that mortality due to those diseases for which curative measures are available is falling more rapidly than mortality from those diseases which are not yet open to medical intervention. ${ }^{8}$ Common sense might suggest this would be so, but it is nice now to have some figures.

I think that Peter Townsend might agree with me that if we are serious in seeking to diminish morbidity and mortality due to social deprivation, we must return to the values of the welfare state and pursue them with greater determination.

1 Ruskin J. Sesame and lilies. London: Smith, Elder and Co, 1865.

2 Townsend $P$. Inequality and the health service. Lancet 1974;i:1179-90.

3 Brotherson J. Inequality: is it inevitable? In: Peel J, Carter CO, eds. Equalities and Inequalities in Health. London: Academic Press, 1976.

4 Whitehead M. The health divide. 2nd ed. London: Penguin, 1992.

5 Marmot MG, Shipley MJ, Rose G. Inequalities in death - specific explanations of a general pattern? Lancet 1984;i:1003-6.

6 Barker DJP. The fetal and infant origins of adult disease. BMF 1990;301:1111.

7 Department of Health and Social Security. Health Services development: Cour report on child health services. London: HMSO, 1978.

8 Boys RJ, Forster DP, Jojan P. Mortality from causes amenable and nonamenable to medical care: the experience of eastern Europe. BMf 1991;303: 879-83.

\title{
Metachromatic leukodystrophy: two sides of a coin
}

\author{
Robert Jeffery, Alison Jeffery
}

Like all parents, we dreaded the birth of a handicapped child. We had not realised that our love for that child would both compound and leaven the heartbreak and hard work.

Our story is the typical one of initial concern about her development, the gradual appearance of neurological signs, and eventually the realisation that the disorder was progressive. We were fortunate that a diagnosis was possible: many families have to cope with neurodegenerative diseases that have not yet been characterised. For us the prognosis could be explained, although the timescale in metachromatic leukodystrophy is variable. The deficient enzyme and the gene have been identified and some of the individual mutations are known; relatives can be screened and early antenatal diagnosis performed. Of course, these opportunities bring their own ethical problems.

Soon after diagnosis, we learned of the treatments available, mostly recently developed and with uncertain results. By coincidence, the Royal Manchester Children's Hospital, $3 \mathrm{~km}$ from our home, has an international reputation in this field. The specialists' advice, a literature search, and a phone call to a leading authority in America led us to the conclusion that bone marrow transplantation was more likely to prolong the decline then prevent it in Fiona's case. We were aware of the clinicians' differing opinions and have been at ease with the course we took. Some people insisted we must not give up hope; we found it simpler to accept what we could not change, to take each day as it came and accompany our daughter along her difficult journey as best we could. There is no cure, but there are decisions to be made along the way and the prediction of our physician that each choice would come naturally when the time came has been fulfilled.

\section{Distress and helplessness}

It is deeply distressing to watch one's little girl decline from being a late walker at 18 months to become a helpless creature at the age of 3-paralysed, demented, and blind. There have been hints that she might be vaguely aware of her diminishing ability; that the paralysis preceded the dementia and that her senses 


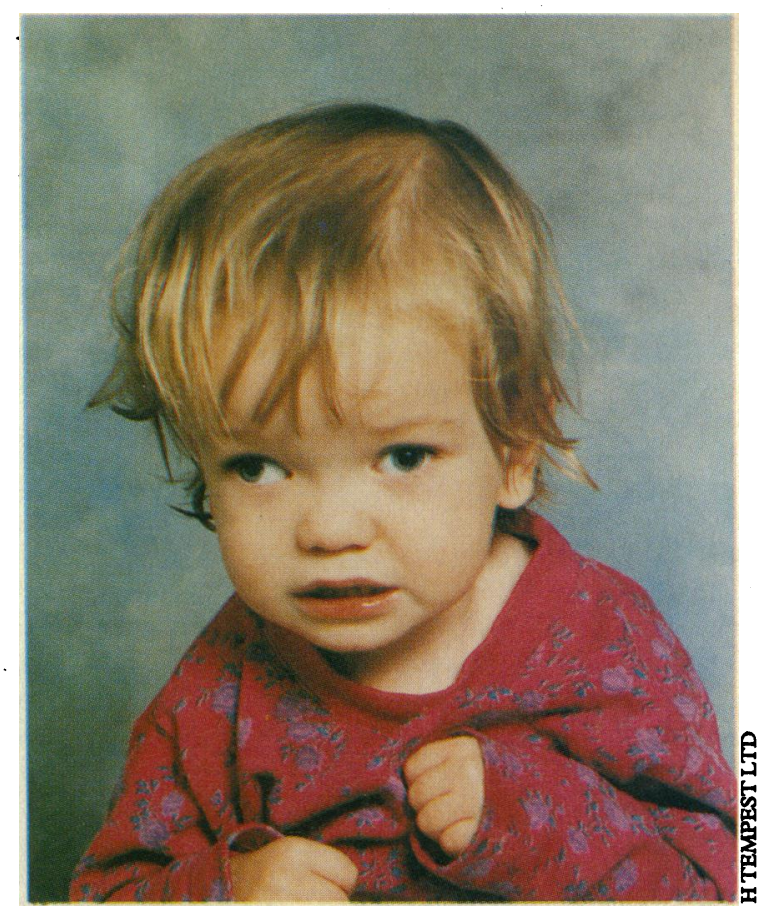

When each week seemed to rob Fiona of one more pleasure, she developed a touching divergent squint which symbolised her vulnerability

have faded before she has ceased to care. One of the most difficult features is our feeling of helplessness; that soothing lullabies and cuddling increasingly cannot ease her distress. The irritability and inconsolability have, however, responded to morphine in combination with chloral and diazepam, delivered through the nasogastric tube and mixed with the continuous feed at night. She now seems to have entered a more peaceful stage, though she still gets very upset when she is moved.

We have known what it is to be struck dumb, leaving unfortunate friends on the end of a dead telephone line. It has often been kindness rather than sadness that has caused tears to well up; our families, friends, and helpers have provided invaluable support, and we have drawn strength from the church and local community. Our friend from the Crossroads charity not only has enabled Alison to take our other child, Christopher, out after school, but also has supper waiting on her return. We have also been grateful for the skill and kindness of the professionals.

\section{Hospices and schools}

We were introduced to Francis House Hospice early on and, like many new arrivals, felt a fraud as our little girl played with the toys as some of the children sat passively. Initially, the staff helped us work through the emotional turmoil. We came to realise how important those first short visits were in enabling the whole family to get to know our new friends at a time when Fiona's mischievous and stubborn character could still be expressed. Later, particular people at the hospice have continued to provide spiritual support and friendship and Fiona sometimes stays overnight to enable us to treat Christopher and ourselves to an outing. We have been aware of others in more difficult circumstances than our own, with a single parent, several affected children, or a different time course.

If children's hospices touch the hearts of the public, special schools are the Cinderella of the caring network, often struggling for the basic resources such as adequate seating. Fiona was accepted for Parkes Field Special School when she was two and was still thought to have mild ataxic cerebral palsy. During the first six months? she enjoyed the singing, craft activities, hydrotherapy 5 and soft play area. The staff shared our pain as she declined. Even as her abilities slipped away, she enjoyed the other children's company, and we will decide next term whether she is still aware enough to justify the upheaval of the journey to school. We hope to provide a modified tricycle in recognition of Fiona's happy time there.

\section{Not as bleak as the darkest fears}

Parenthood is an enriching and humbling experience. It is a paradox that parents have such aspirations for their children and yet can love a child despite all she does, is, or is not. Part of the grief following the devastating news of a fatal illness is the crushing of these aspirations-the loss of the child who could have been. This image is sometimes painfully rekindled by. seeing other girls of a similar age. Yet the protective love one feels is heightened by the child's dependence. News of the diagnosis also provokes pity for the child and fear of the journey ahead. There is no denying the black cloud lurking over our lives, causing periods of anguish and despair. But for all the sadness, it is not as, bleak as the darkest fears; the hurt persists, but laughter does return. Wishing for it all to be over-for the child and the family-yet being unable to bear to say goodbye are not irreconcilable alternatives; they are two sides of the same coin.

Some of these thoughts originated from Dr Richard Newton and others who have helped us come to terms with Fiona's illness. We thank $H$ Tempest Ltd for permission to reproduce the photograph.

Donations for equipment can be sent to Parkes Field School Fund, c/o the Headmistress, Parkes Field School, Barton Road, Swinton, Manchester M27 1LP.

\section{Katy}

Six months old

\author{
Wakes us at dawn \\ with a soprano chorus \\ Dances on her back \\ to music we cannot hear \\ Conducts the orchestra \\ with a hand or rattle \\ Smiles, as she bends \\ her body into a grin \\ Puts fists in her mouth \\ to make her tongue talk \\ Opens her arms to us \\ and our hearts to her \\ Fastens a wet medal \\ of saliva to my shirt
}

\section{Curls her tongue and toes as she takes her bottle \\ Kicks against my chest like my heart beating \\ Watches her mobiles and parents go round \\ Stares out into space at worlds we cannot see \\ Shows us how we were light years distant \\ Lifts hands above head and surrenders to sleep}

From Recovery by Chris Woods, available from Enitharmon Press, 36 St George's Avenue, London N7 0HD. 